\title{
Author Correction: Biologically driven DOC release from peatlands during recovery from acidification
}

\author{
Hojeong Kang ${ }^{1}$, Min Jung Kwon ${ }^{1,4}$, Sunghyun Kim ${ }^{1,5}$, Seunghoon Lee ${ }^{1,6}$, Timothy G. Jones ${ }^{2}$, Anna C. Johncock ${ }^{2}$,
} Akira Haraguchi ${ }^{3} \&$ Chris Freeman ${ }^{2}$

Correction to: Nature Communications; https://doi.org/10.1038/s41467-018-06259-1; published online 18 September 2018

The original version of this Article contained an error in the Acknowledgements, which incorrectly omitted from the end the following: 'In particular, we thank the staff of the Centre for Ecology and Hydrology (including A. Burden, N. Ostle and C. Evans) in relation to a NERC grant involving CF \& TJ (NE/E011748/1; 2007-2010), which established the sites from which the UK samples were subsequently collected.' This has been corrected in both the PDF and HTML versions of the Article.

Published online: 31 October 2018

\begin{abstract}
(c) (i)
Open Access This article is licensed under a Creative Commons Attribution 4.0 International License, which permits use, sharing, adaptation, distribution and reproduction in any medium or format, as long as you give appropriate credit to the original author(s) and the source, provide a link to the Creative Commons license, and indicate if changes were made. The images or other third party material in this article are included in the article's Creative Commons license, unless indicated otherwise in a credit line to the material. If material is not included in the article's Creative Commons license and your intended use is not permitted by statutory regulation or exceeds the permitted use, you will need to obtain permission directly from the copyright holder. To view a copy of this license, visit http://creativecommons.org/licenses/by/4.0/.
\end{abstract}

(C) The Author(s) 2018

\footnotetext{
${ }^{1}$ School of Civil and Environmental Engineering, Yonsei University, Seoul 03722, Korea. ${ }^{2}$ School of Natural Sciences, Bangor University, Bangor LL57 2 UW, UK. ${ }^{3}$ The University of Kitakyushu, Kitakyushu 802-8577, Japan. ${ }^{4}$ Present address: Korea Polar Research Institute, Inchon 21990, Korea. ${ }^{5}$ Present address: Smithsonian Environmental Research Center, Edgewater 21037-0028, MD, USA. ${ }^{6}$ Present address: Shine Biopharm Inc., Seoul 06536, Korea. These authors contributed equally: Hojeong Kang, Chris Freeman. The original article can be found online at https://doi.org/10.1038/s41467-018-06259-1.

Correspondence and requests for materials should be addressed to H.K. (email: hj_kang@yonsei.ac.kr) or to C.F. (email: c.freeman@bangor.ac.uk)
} 